\title{
Analysis on Communication Effects of Cultural Quiz Show
}

\author{
Shengnan $\mathrm{Yu}$ \\ Heihe University \\ Heihe, China 164300
}

\begin{abstract}
Nowadays, with the development of "panentertainment", screens are full of "reality show". Cultural programs draw people's attention within a short time because of its popularity and good reputation. It is the appearance of new cultural education programs and the cultural heritance activity with profound significance. Attentions, identification and inheritance of traditional culture caused by programs are analyzed through cognition, psychology and attitude and action produced by communication effects.
\end{abstract}

Keywords—cultural quiz; communication effects; traditional culture

\section{INTRODUCTION}

During the Spring Festival of 2017, Chinese Poetry Conference (the second seas on) is broadcast on CCTV-1 and CCTV-10, letting cultural quiz show get high audience rating. With fierce competition, the program brings spiritual satisfaction and audio-visual entertainment, and plays positive role in spreading traditional culture and mainstream values. In 2013, hot broadcast of programs related to Chinese characters such as Chinese Characters Dictation Competition on CCTV and Chinese Spelling Hero on HNTV aroused a heated discussion on Chinese character writing and cultural heritance. Programs broadcast on television stations such as Chinese Poetry, Favorite Chinese Characters, Chinese Lantern Riddles Conference, Chinese Riddle Conference and Chinese Idiom Conference form new program forms of cultural education that integrate culture, education and entertainment. They are collectively called cultural quiz show.

The programs are original. Nowadays, influenced by "panentertainment", phenomenon with homogenization and vulgarization is serious. Screens are full of "reality show". Without heavy investment, excessive packaging and star effect or publicity stunt, cultural programs can stand out in the prime time in the evening through competition with hot IP TV plays and variety entertainment programs with super high popularity, and realize communication value from cognition, psychology and attitude and action, furthest realize the function of television media in inheritance and transmission of traditional culture.

\section{COGNITION: REgAin TRADITIONAL CUlturE}

The effects on cognition mean external information acts on people's consciousness and memory system and cause the increase of people's knowledge quantity and change of cognitive structure. Cultural quiz show has simple forms and pictures and smaller production investment than today's variety entertainment program, but it gets high attentions under the help of television with the strongest social transmissibility. If Chinese Characters Dictation Competition attracts people's attention to Chinese characters and its beauty and arouses people's cultural introspection through writing and explanation of Chinese characters, Chinese Poetry Conference stimulates people's strong interests in understanding and learning traditional Chinese culture under the help of poetry that concentrates the highest realm of spiritual life of Chinese nation.

Traditional Chinese culture has diversified forms. Lyreplaying, chess, calligraphy and painting, literature, verses, ditties, odes and songs can embody the quintessence of traditional culture. For example, poetry is regarded as the spirit of traditional culture and concentrates the highest realm of spiritual life of Chinese nation. In order to "appreciate Chinese poetry, find cultural gene and taste the beauty of life", Ch inese Poetry Conference takes poetry as the carrier to inherit traditional culture and lets people realize the importance of regaining poetry and arouses the enthusiasm of all the people to participate. The second season expands time span of poetry contents, from the Book of Songs to Mao Zedong's poetry. These works have elegant language and deep times brand, contain historical allusions and humanistic features as well as reflect people's thoughts and feelings in specific period. The program uses the most familiar and impressive poetry and stimulates memories and feelings of audiences, letting them understand the quintessence of Chinese poetry and regain traditional Chinese culture in the "familiar strange questions".

The cultural quiz shows are not superficial but have rich connotation. The cognitive changes derive from the explanation of Chinese characters, idioms or poetries, which relate to participators and distinguished guests. Many competitors are stars and appear on Chinese Spelling Hero and Chinese Character Dictation Competition. Attentions are also paid to distinguished guests and hosts who are stars. They serve as referees and explain vocabularies. The "explanation" can popularize Chinese character culture. Meanwhile, the appeal of celebrities also improves audience rating and reputation. The comments of four distinguished guests in Chinese Poetry Conference are finishing touch. When explaining difficulties or topics in poetries, they let the background of poetry reappear so that audiences can 
understand every aspect of ancient and modern life. Under the leadership of cultural quiz shows, the society appears new cultural phenomenon appears and gradually forms new cognitive forms with respect for knowledge, history, culture and erudition.

\section{PSYCHOLOGY AND ATTITUDE: IDENTIFICATION OF TRADITIONAL CULTURE}

Effects on psychology and attitude mean acting on people's ideas and value system and causing emotional changes. Because of the absence of appeal and visual impact in programs of songs and dance, it is difficult to attract audiences, so cultural quiz shows must combine culture and interestingness.

Chinese Characters Dictation Competition directly stimulates people to recognize their Chinese level and pay attention to Chinese characters. Chinese characters are the only ideograph passed down to now and we have to remember almost each of them separately. The development of writing ability of it is the most difficult among main languages in the world. In order to effectively and comprehensively maintain this ability, we must write daily and frequently. The popularization of computer lowers the difficulty in writing Chinese characters. The convenience of electronic text makes people choose computer to write. The ability to write Chinese characters will degrade if we fail to consolidate it through other ways and channels. Chinese characters are important part that carries Chinese civilization and maintains national unity. The deficiency of writing ability will greatly reduce the cultural force of Chinese characters. Under the impact of modern technology, writing through keyboard, screen and forgetting the characters in writing becomes universal. Cultural quiz shows with Chinese characters as carrier focus on Chinese character writing and spread Chinese character culture. Meanwhile, it lets people realize the serious decline of ability in Chinese character writing, arouses their attention and love for Chinese character writing. People can understand cultural connotation and unique charm of Chinese characters. A profess or of history in Fudan University, Qian Wenzhong says, "The writing of Chinese characters is a tool, life style and cultural identity".

The success of Chinese Characters Dictation Competition, Chinese Idio m Conference and Chinese Riddle Conference lets audiences regain traditional culture and realize cultural identity. Chinese Poetry Conference pays more attention to the combination of reason and sensibility, innovates in forms and contents, laying foundation for inheritance and transmission of excellent traditional Chinese culture and forming guidance of public opinion. The program packing integrates Chinese traditional cultural ele ments and presents elegant Chinese style through wash painting. In the second season, the magnificent water stage is built in the studio and forms "a poem replete with graphic description and a painting full of poetic grace", together with the super gorgeous large screen. Poetry recitation appears at the beginning of the program, driving the transmission of traditional culture. Crossword puzzle, building up a sequence with poetries and guessing poems through drawing full of interestingness are also designed. The "Feihua Game" added in the second seas on checks the poetry reserves of competitors and lets audiences experience the exquisite Chinese poem. Cultural quiz shows use popular ways to guide the cultural gene of Chinese people through the powerful attraction and artistic appeal.

\section{ACTION: INHERITANCE AND TRANSMISSION OF TRADITIONAL CULTURE}

Effects on action mean changes are expressed through people's statements and actions. The hot broadcast of Chinese Characters Dictation Competition and Chinese Spelling Hero arouses people's discussion on Chinese character writing and inheritance of Chinese character culture. Chinese Poetry Conference drives people to learn and chant poetries. The program group of Chinese Characters Dictation Competition thinks it is a "profound activity of cultural inheritance". "The civilization transmission of writing and preparation of nation" advocates the public to write and protect Chinese characters, love Chinese characters, Chinese and Chinese culture. Obviously, the program pursues cultural inheritance and civilization transmission through Chinese character writing and lets Chinese people realize the importance of taking precautions.

Cultural quiz shows achieve inheritance and transmission of traditional culture through interactivity. In the recording of Chinese Characters Dictation Competition, competitors answer at the field. Besides, the dictation experience groups are set outside the studio. After the examination of each word group, the host notifies the writing accuracy of adult audiences. The result is not ideal. So me net friends show their dictation records on weibo and most have poor performance. They sigh with emotion that they forget the knowledge learnt before. In the program of Chinese Poetry Conference, the group formed by one hundred people and competitors answer questions together. The points of competitors depend on the number of people in the group who give wrong answers. In the link of "Feihua Game", competitor who gets the highest score and the person who takes the first prize in the group take turns to recite poetries containing keywords. The winner directly competes with the previous winner. People outside the studio can answer questions through scanning the $\mathrm{QR}$ code. It strengthens people's consciousness and learning of traditional culture and lets them actively inherit and carry forward traditional Chinese culture.

Under this background, on one hand, it guides the development direction for program production, meets requirements of audiences and combines culture and entertainment. The enthusiasm of audiences is aroused to inherit culture. Telev ision media can effectively shoulder social responsibilities. On the other hand, the learning of traditional culture is popular. Many bookstores establish learning corner. More and more students learn calligraphy, idioms and poetry. Cultural competitions organized by schools and civil groups grow vigorously. However, the learning and inheritance of traditional culture is not maintained by the heat of topic brought by hot broadcast of some programs. We should carry out self-inspection in inheritance of traditional culture and understand the ability of the next generation in cultural inheritance, and then continuously appreciate its charm and the spiritual culture. 


\section{CONCLUSION}

In conclusion, the hot broadcast of cultural quiz shows lets original programs see hope and avails the formation of good social ethos. First, for television media, it guides the development direction for program production, meets the requirements of audiences and combines culture and entertainment, furthest arouses the enthusiasm of audiences to inherit culture, better letting cultural programs on TV shoulder social responsibilities effectively. Second, for cultural education in society, the learning of traditional culture is popular. Many bookstores establish learning corner. An increasing number of students learn calligraphy, idioms and poetries. Cultural contests organized by schools and civil groups grow vigorously. Third, for local creation, with the unique Chinese characteristics, Chinese Characters Dictation Competition and Chinese Poetry Conference let producers no longer think only the introduction of program pattern in foreign countries is the guarantee of audience rating. Finally, the learning and inheritance of traditional culture cannot be maintained by the heat of topic brought by hot broadcast of some programs. We should carry out self-inspection in inheritance of traditional culture and understand the ability of the next generation in cultural inheritance, and then continuously appreciate the charm of Chinese characters, idioms, poetries and riddles as well as the extensive and profound culture.

\section{REFERENCES}

[1] Guo Qingguang. Communication Course (Second Edition) [M], Beijing: China Renmin Universit y Press, 2011

[2] Li Zi. Discussion on Exploration and Innovation of Cultural Programs on TVthrough Chinese Spelling Hero and Chinese Characters Dictation Competition [J], China Radio and TV Academic Journal, 2013(10)

[3] Xu Xiaohui, Li Rui. Discussion on Inheritance and communication of Traditional Chinese Culture through Television from Chinese Poetry Conference [J], Cont emporary T V, 2016(7)

[4] Zou Jiani. Research on Innovative Strategy of Original Traditional Cultural Programs-Take Chinese Poetry Conference on CCTV as an Example [J], Media, 2016 (7) 